\title{
Pharmacovigilance and incidence of adverse drug reactions in hospitalized pediatric patients: a mini systematic review
}

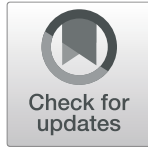

\author{
Zakir Khan ${ }^{1,2^{*}}$ (D, Khayal Muhammad ${ }^{3}$, Yusuf Karatas ${ }^{1,4}$, Cagri Bilen ${ }^{1}$, Farman Ullah Khan ${ }^{5}$ and Faiz Ullah Khan $^{5}$
}

\begin{abstract}
Background: Pharmacovigilance is an identifying and responding process against an adverse drug reaction (ADRs) problem encountered in the drug administration. ADRs are among the common reasons for morbidity and fatality in pediatrics throughout the globe.

Main body: A systemic review of the previous 10 years (2010-2019) published studies were taken into consideration to describe observational studies on ADRs and to determine the incidence and characteristics of ADRs in pediatrics. Electronic relevant literature was searched in PMC, PubMed, Google Scholar, and OvidSP databases using MESH heading and text words. The titles, text, and abstracts were checked for patients below 18 years of age, nature of ADRs, observational studies (prospective or retrospective), and maximum information was recorded to count their frequency. The studies which discussed specific or particular drug exposures were not selected in this review. Of the 36,689 titles retrieved, 27 studies were selected for full-text review. Ten observational studies were added in the final review. Observational studies on pediatric were carried out in seven distinct nations. The predominant study design within observational methodological studies was prospective $(n=5,50 \%)$. The overall average occurrence of ADRs incidence was 9.52\%. ADRs reporting in male patients (54.6\%) were more than females (45.4\%). The severe types of ADRs were reported in four studies. Anti-microbials were the most common class of drugs related to ADRs.
\end{abstract}

Conclusion: This systematic review reveals that ADRs in pediatrics are serious public health problems. Periodic drug surveillance studies are mandatory for the safe and appropriate usage of medicines in pediatrics.

Keywords: Pediatrics, Adverse drug reactions, Pharmacovigilance, Hospital, Review

\section{Background}

Pharmacovigilance is an identifying and responding process against a problem encountered in the drug administration [1]. The advancement of drugs in the previous decades has brought surprising benefits for the patients, concurrently the incidence of adverse drug reactions (ADRs) has also increased notably [2]. World

\footnotetext{
* Correspondence: zakirkhan300@gmail.com

${ }^{1}$ Tıp Fakültesi, Tıbbi Farmakoloji Anabilim Dalı, Çukurova Üniversitesi, Sarıçam, 01330 Adana, Turkey

2Department of Pharmacy, Quaid-i-Azam University, Islamabad 45320,

Pakistan

Full list of author information is available at the end of the article
}

Health Organization (WHO) describes ADR as "a response to a drug which is harmful, unintended and occurs at normal doses used for the treatment, diagnosis, and prophylaxis of a disease" [3]. ADRs are among the common reasons for morbidity and fatality throughout the globe [4]. Ultimately, these issues have a major impact on public health due to imposing a significant economic load on society and already stretched healthcare systems [5].

The safety of medicines in pediatrics is a global issue and proper knowledge about pharmacovigilance and spontaneous reporting of ADRs is the most essential measure to boost the safe use of therapeutic agents $[6$,

\section{Springer Open}

(c) The Author(s). 2020 Open Access This article is licensed under a Creative Commons Attribution 4.0 International License, which permits use, sharing, adaptation, distribution and reproduction in any medium or format, as long as you give appropriate credit to the original author(s) and the source, provide a link to the Creative Commons licence, and indicate if changes were made. The images or other third party material in this article are included in the article's Creative Commons licence, unless indicated otherwise in a credit line to the material. If material is not included in the article's Creative Commons licence and your intended use is not permitted by statutory regulation or exceeds the permitted use, you will need to obtain permission directly from the copyright holder. To view a copy of this licence, visit http://creativecommons.org/licenses/by/4.0/. 
7]. The very early case of a safety issue that drives to a pharmacovigilance reflection, published in 1877 in the British Medical Journal, was the chloroform issues. In 1898, the commercialization of diacetylmorphine was the second issue that occurred, latterly called heroin, which started to be addictive at the start of the 1910s (Only in the USA, almost 0.5 million dependent patients were reported) [8]. Amid the 1960s, numerous babies were born with agenesis of the limbs and phocomelia as an adverse effect of thalidomide. In 1957, Thalidomide was launched into the market as a safe over-the-counter hypnotic/sedative drug; latterly, it was used to control nausea in pregnant women. This was afterward confirmed in the same year that thalidomide usage was responsible for $20 \%$ of the increase in phocomelia and agenesis of the limb's defects [7].

In reply to the thalidomide tragedy, in 1968, the WHO earlier built up its plan for International Drug Monitoring. Later on, a WHO collaborating center in 1978 named "Uppsala Monitoring Centre (UMC)" was designed to support the specified program [7]. Worldwide, pharmacovigilance studies are the basic demand of the time for an invariable audit of unwanted effects in community and hospitals. Healthcare professionals, i.e., physicians, pharmacists, nurses, and other paramedical staff are all guided about the reporting ADRs, which consequently leads to high medicine safety for the population [6,9-11].

Obtaining, ordering, reproducing, checking, handling, distributing, and managing are the medication stages manner, and mistakes/errors in pediatric medicine may occur at any stage $[6,7]$. Medication errors are any preventable action that may injure the patient [9]. Pediatric populations are at greater risk than adults for medication errors as they have immature physiology and developmental disabilities that impair their ability to communicate and self-administer medications. Studies reported that medication errors in pediatrics were 3 times higher than in adult populations. Pediatrics poses a complex and unique set of risks, mainly due to the large differences in body mass, which require doses to be measured individually based on patient age, weight or body surface area, and clinical condition [7, 8]. Such variations raise the probability of errors, particularly dosing mistakes. Additionally, drug formulations are frequently extemporarily formulated to meet the requirement for low doses in such patients, and there is a lake of information on pediatric doses and indications [7]. The possible types of medication errors in pediatric populations are wrong drug, wrong route of administration, an error of use, incorrect or out-of-time, incorrect frequency, incorrect dosage, incorrect case, drug interfaces, intravenous conflict, ignoring mistakes, and incorrect rate of intravenous drug administration [2, 3, 5, 7]. Medication error ultimately leads to an acute to severe ADRs $[2,7,12]$.
Previous studies have revealed that almost $5 \%$ of all hospital admissions are as a result of ADRs, and that 5\% of hospital-admitted children will face an ADR within their stay in hospital and 5\% of all acute hospitalizations originated from ADRs [7, 12-14]. Children are more prone to ADRs as they rarely express their own drug therapy experiences [15]. Therefore, medications in children have a high risk of developing different types of ADRs [16]. When compared to adults, children can have somewhat more severe side effects. Hence, ADRs can be a major reason for morbidity and mortality in children [17]. Furthermore, very low attentiveness has been given to ADRs in newborns, toddlers, children, and teenagers $[18,19]$. Therefore, the basic purpose of the current study was to perform a systematic review of observational studies on ADRs in hospitalized children during the previous decade and to determine the frequency and characteristics of ADRs.

\section{Main text \\ Search strategy}

A comprehensive and systematic search in different databases, i.e., PubMed, PMC, Google Scholar, and OvidSP-related published English literature was identified from 1 January 2010 to 31 December 2019. These databases were searched to identify existed literature of Pharmacovigilance and ADR in hospitalized admitted pediatric patients. Basic search terms were Pharmacovigilance OR drug therapy/adverse effects OR adverse drug reaction reporting system OR adverse effects/ pharmaceutical preparations" AND "child OR pediatrics OR child-preschool" AND "Observational studies." The basic search strategy and keywords were modified as appropriate according to the searched database (Supplementary file 1).

\section{Eligibility criteria}

Basic screening of search results was carried out by the first author then the second and third reviewers independently reviewed and examined the titles and abstracts to find out potential studies with full texts. Only those papers were included if they referred to ADRs in pediatrics of age 0 to 18 years, observational studies (prospective or retrospective), and maximum information was reported to calculate their frequency while those studies were excluded which contained ADRs referred to adult-only or a mixture of adults and children, and studies that discussed specific or particular drug exposures and did not separate the results. We searched and screened those studies and electronic bibliographic articles that were similar to the already described inclusion criteria and were selected and counted in the final analysis. 


\section{Data extraction}

All eligible studies were assessed to meet inclusion criteria. Any discrepancies at each stage of selection were discussed by a reviewer and resolved by consensus. All the investigators separately analyzed the methodology, results, and criteria of every study by using standard data extracted proforma. The information related to the proportion of pediatrics who showed ADRs was obtained from the selected studies. The details about ADRs severity and probability were taken into consideration, and ADRs were categorized as severe if they were serious or mortal. Other information included in the analysis contains the study design, country, year, study setting, duration of the study, population studied, mean age, most commonly reported ADRs, and drugs. The final results of the review were summarized narratively, and major characteristics of the study were arranged in tabular form.

Of the 36,689 titles retrieved by the basic electronic initial search strategy, 27 studies were selected for complete text review. After the removal of 15 research articles that were found irrelevant to a primary research question, 12 full-text publications were retrieved. Two more studies [20,21] were excluded because they did not report the amount of the population disclosed to drug therapy, causing the calculation of ADR frequency inadequate. Finally, 10 studies were evaluated for eligibility in the final review (Fig. 1).

Observational studies on pediatric were carried out in seven distinct nations. The predominant study design within observational methodology was prospective $(n=$ $5,50 \%)$ [22-26], retrospective-prospective $(n=1,10 \%)$ [16], cross-sectional $(n=1,10 \%)$ [27], and cohort $(n=3$, $30 \%$ ) [28-30]. All of the reports concerning the ADR incidence in hospital admitted pediatrics. The recorded ADR frequency ranged from 1.7 to $25.4 \%$ amid the studies (Table 1). The estimated total average incidence rate was $9.52 \%$. Further details about the final included studies are summarized in Table 1.

The overall ADRs reporting in male patients were more than females. The causality assessment of ADRs in included studies revealed that the most common types
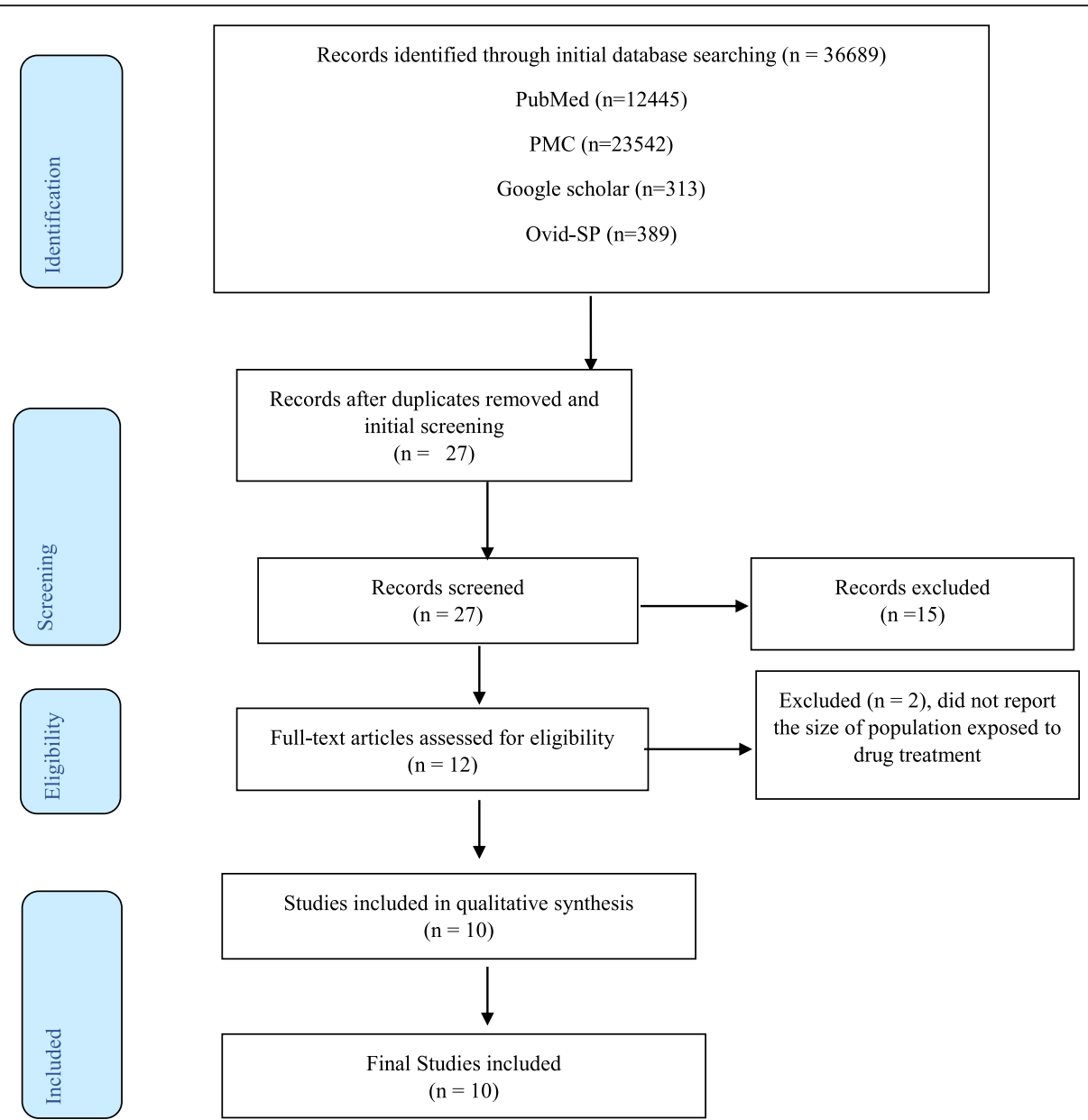

Fig. 1 PRISMA flow diagram 
Table 1 Summary of observational studies $(n=10)$ and ADRs incidence rate

\begin{tabular}{|c|c|c|c|c|c|}
\hline Studies (year) (reference) & Country & Study design & $\begin{array}{l}\text { Pediatrics population } \\
\text { studied }(n)\end{array}$ & Duration of study & $\begin{array}{l}\text { Incidence of } \\
\text { ADRs \% (n) }\end{array}$ \\
\hline Gallagher RM et al. (2011) [22] & UK & Prospective & 822 & 2 weeks & $3.3 \%(27)$ \\
\hline Gallagher RM et al. (2012) [23] & UK & Prospective & 6821 & 1 year & $3.6 \%(249)$ \\
\hline Khan LM et al. (2013) [16] & Saudi Arabia & Retrospective-Prospective & 1200 & 1 year & $6.3 \%(76)$ \\
\hline Dash M et al. (2015) [29] & India & Prospective cohort & 500 & 1 year & $25.4 \%(127)$ \\
\hline Gholami K et al. (2015) [24] & Iran & Prospective & 658 & 6 months & $4.1 \%(27)$ \\
\hline Rivas AB et al. (2016) [28] & Spain & Prospective cohort & 313 & 1 year & $17.2 \%(116)$ \\
\hline Salas Rdl et al. (2016) [30] & Colombia & Prospective cohort & 772 & 6 months & $20.2 \%(156)$ \\
\hline Kurian J et al. (2016) [25] & India & Prospective & 1082 & 6 months & $5.9 \%(64)$ \\
\hline Vázquez-Alvarez AO et al. (2017) [27] & Mexico & Prospective cross-sectional & 1083 & 6 months & $1.7 \%(19)$ \\
\hline Sindhu AR et al. (2019) [26] & India & Prospective & 200 & 6 months & $7.5 \%(15)$ \\
\hline
\end{tabular}

of ADRs were probable followed by definite/certain and possible. The severity of ADRs was observed in seven studies and showed the highest percentage of ADRs were mild and moderate. Severe types of ADRs were also expressed in four studies. Amid the studies, the severity rate of ADRs was from 5.6 to $42 \%$ (Table 2).

The most commonly affected system due to ADR were skin $(n=5)$, the digestive system $(n=3)$, and the circulatory system $(n=2)$. The most frequently reported ADRs were urticaria/rashes, vomiting, diarrhea, and neutropenia. Almost 70\% $(n=7)$ of the studies were showed severe ADRs to anti-microbials. Anti-epileptic, anticonvulsants, and anti-neoplastic agents were the next frequently reported therapeutic classes (Table 2).

\section{Discussion}

The findings observed from this systematic review are obtained from a geographically variegated sample of observational drug surveillance studies. This information offers to understand the healthcare team about the major influence of ADRs in hospitalized pediatric patients in various healthcare settings. Furthermore, the results of this review might have a significant impact on the reporting, management, and design of pediatric surveillance studies.

Our results reveal that the estimated average ADR incidence in all selected studies was $9.52 \%$. The difference in ADRs rate among the studies is due to the variation in the selected settings, data collection methods, and methodologies used. The previously published metaanalyses about the incidence of ADRs in the pediatric patients found that the reported ADR incidence rate was in the range of 4.37 to $16.78 \%$ amid the studies and meta-analytic estimated average was 9.53\% [18]. According to the study which was conducted in 38 different Italian hospitals and recruited 1332 hospitalized patients reported that the onset of at least 1 ADR was associated with a median of 4-day stay prolongation [31].
ADR reporting in male patients were more than females in included studies. It is stated that the difference in susceptibility to ADRs between gender is due to physiological features, such as weight, fat percentage, intestinal transit velocity, genetic, and hormonal variations [32].

The severe types of ADRs were also reported in four studies included in this systematic review. These results suggest that ADRs are a serious public health problem in the pediatric population. The assessment of ADR severity is crucial to undertake substantial steps against the drug continuation decision. It is stated that severe ADRs are responsible for the increased duration of stay and also impose a financial load on patients [18, 33, 34].

The majority of the studies observed that antimicrobials were the most frequent class of drugs related to ADRs. Anti-microbials are prescribed to half $(50 \%)$ of all hospitalized patients and it is also one of the costliest categories of drug expenditure [35]. Higher usage of anti-microbials for prophylactic and therapeutic purposes may be a reason for ADRs in hospitalized patients [2]. Inappropriate usage of anti-microbial is associated with high ADRs incidence and ADRs-related admissions in hospitals [36, 37].

The results of ADRs are almost always biased by the rate of actual reporting. Some relevant information related to ADRs, such as prolongation of stay, financial burden information, ADR ratio in general intensive care units (ICUs) or wards, intravenous or oral drugs, night dose, or day dose were not evaluated by the studies included in this systematic review. Such types of data are important to emphasize on the careful collection of information while performing ADR reporting and help prevent ADRs in the first place. These important points should be included and need to be evaluated in future studies for the meticulous collection of data.

Despite many advantages, our systematic review also had some limitations. Firstly, we selected only those 


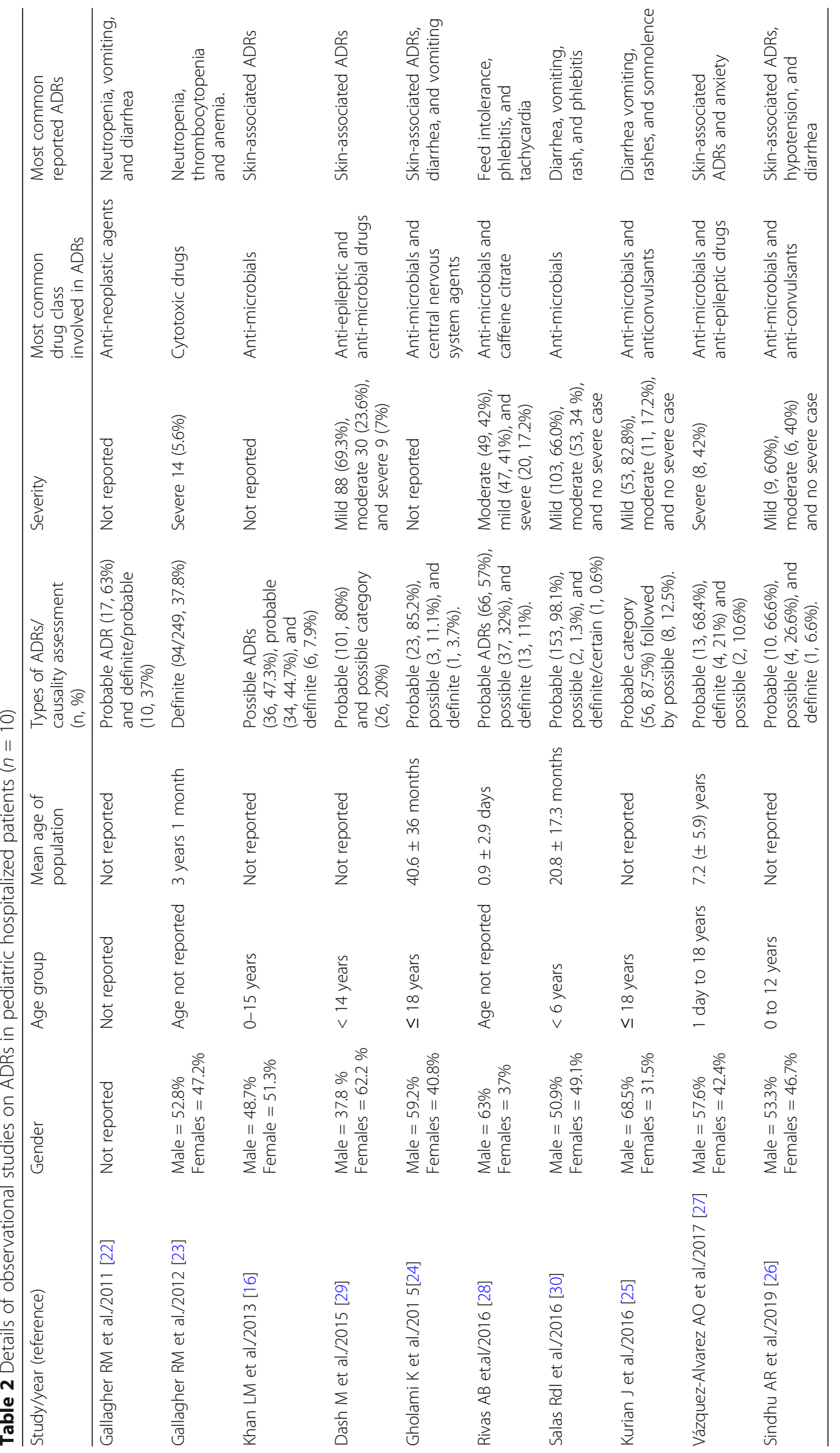


observational studies which recruited hospitalized pediatric populations and were observed ADRs via prospective or retrospective approach. Secondly, yet, even amid the methodologically sound and most homogeneous research papers, there is considerable variation in the reported ADRs incidence. Present heterogeneity is just partially described by the various number of medications administrated to pediatrics in every study. Thirdly, we performed a keen search, but this resulted in a high number of titles and abstracts for review. To reduce uncertainty, we used comprehensive exclusion and inclusion criteria and selected a traditional approach of selecting studies for full-text review where ambiguity is there. Fourthly, the other predictors such as diagnosis and prescription patterns of drugs could not be measured in the analysis as they were not properly and homogeneously reported in selected studies. Fifthly, the findings of this review are hard to confidently extrapolate to an international level because most of the studies were carried out in a few countries. Sixthly, the current systematic review mainly analyzed the studies of hospitalized pediatric patients who admitted in different wards and thus should not necessarily be generalized to all pediatric populations. Finally, for compelling causes associated with the feasibility of the review, we did not consider evidence taken from grey literature. This error may have raised a question about the accuracy of the calculated estimated average incidence rate [38] but not the relevance of findings and the implications for practice.

\section{Conclusion}

Adverse drug reactions of medications are the main causes of morbidity and mortality around the world. This mini systematic review describes that ADR in hospitalized pediatrics patients is a potential public health problem. The drug surveillance studies, prescription patterns audits, and clinical data in pediatric patients should be recorded in a logically accepted way for better analysis in the future. This will help the statistical technique of metanalysis to produce effective information for the proper prevention of ADRs in pediatrics. Pediatric physicians, pharmacologists, pharmacists, and other healthcare personals involved in the treatment of pediatrics should make all efforts to provide proper information, logical communication, and appropriate education regarding the rational use of medicines. The future studies for the appropriate assessment of prescribing practices in various healthcare settings and collaborative efforts for the avoidability of ADRs are needed for better pharmacovigilance activities and patient safety.

\section{Supplementary information}

Supplementary information accompanies this paper at https://doi.org/10. 1186/s43054-020-00038-8.

Additional file 1. Electronic search strategy.

\section{Abbreviations}

ADRs: Adverse drug reactions; MESH: Medical Subject Headings; WHO: World Health Organization; USA: United States of America; PRISMA: Preferred Reporting Items for Systematic Reviews and Meta-Analyses; UK: United Kingdom

\section{Acknowledgements}

Not applicable

\section{Authors' contributions}

ZK and YK were involved in the concept, design, and data collection of the study. KM, CB, FK, and FUK carried out the critical evaluation and interpretation of the data. ZK, KM, and YK wrote the first draft of the manuscript, and all authors contributed to subsequent drafts. All authors revised the manuscript and approved the final version for submission.

\section{Funding}

Not applicable

Availability of data and materials

All the data are available inside the article.

Ethics approval and consent to participate Not applicable

Consent for publication

Not applicable

\section{Competing interests}

Not applicable

\section{Author details}

${ }^{1}$ Tıp Fakültesi, Tıbbi Farmakoloji Anabilim Dalı, Çukurova Üniversitesi, Sarıçam, 01330 Adana, Turkey. ²Department of Pharmacy, Quaid-i-Azam University, Islamabad 45320, Pakistan. ${ }^{3}$ Department of Pharmacy, Comsat University, Abbottabad Campus, Islamabad, Pakistan. ${ }^{4}$ Pharmacovigilance Specialist, Balcalı Hospital, Cukurova University, 01330 Adana, Turkey. ${ }^{5}$ Department of Pharmacy Administration and Clinical Pharmacy, School of Pharmacy, Health Science Centre, Xi'an Jiaotong University, Xi'an, China.

Received: 20 March 2020 Accepted: 12 July 2020

Published online: 03 August 2020

\section{References}

1. International Society of Pharmacovigilance (ISOP). 18th ISOP Annual Meeting "Pharmacovigilance without borders" Geneva, Switzerland, 11-14 November, 2018. Drug Saf. 2018; 41(11):1103-1273. Available at: doi.https:// doi.org/10.1007/s40264-018-0719-2. Accessed 02 Feb 2020.

2. Venkatasubbaiah M, Reddy PD, Satyanarayana SV (2018) Analysis and reporting of adverse drug reactions at a tertiary care teaching hospital. Alexandria Med J 54(4):597-603

3. World Health Organization (WHO).The importance of pharmacovigilance. 2002. Available at: https://apps.who.int/iris/handle/10665/42493. Accessed 02 Feb 2020.

4. Chokshi A, Sifri Z, Cennimo D, Horng H (2019) Global contributors to antibiotic resistance. J Global Infect Dis 11(1):36

5. Patsuree A, Krska J, Jarernsiripornkul N (2016) Experiences relating to adverse drug reactions in the community: a cross-sectional survey among patients and the general public in Thailand. Expert Opin Drug Saf 15(3):287295

6. Güner MD, Ekmekci PE (2019) Healthcare professionals' pharmacovigilance knowledge and adverse drug reaction reporting behavior and factors determining the reporting rates. J Drug Assess 8(1):13-20 
7. Salas RDL, Soto CMV. Pharmacovigilance in Pediatric Population Pharmacovigilance: IntechOpen; 2019. Available at: https://www.intechopen. com/books/pharmacovigilance/pharmacovigilance-in-pediatric-population. Accessed 03 Feb 2020.

8. Jones JK, Kingery E. History of pharmacovigilance. Mann's pharmacovigilance. 2014:11-24. Available at: doi.https://doi.org/10.1002/ 9781118820186.ch2.

9. Santosh K, Tragulpiankit P (2011) Pharmacovigilance: an overview. Mahidol Univ J Pharmaceutical Sci 38(1-2):1-7

10. Sales I, Aljadhey H, Albogami Y, Mahmoud MA (2017) Public awareness and perception toward adverse drug reactions reporting in Riyadh, Saudi Arabia. Saudi Pharm J 25(6):868-872

11. Elkalmi R, Hassali MA, Al-lela OQ, Awadh AIJ, Al-Shami AK, Jamshed SQ (2013) Adverse drug reactions reporting: knowledge and opinion of general public in Penang, Malaysia. J Pharm Bioallied Sci 5(3):224

12. Angamo MT, Chalmers L, Curtain CM, Bereznicki LR (2016) Adverse-drugreaction-related hospitalisations in developed and developing countries: A review of prevalence and contributing factors. Drug Saf 39(9):847-857

13. Savlı E, Savlı E The Importance of Pharmacovigilance and Ecopharmacovigilance in Nursing Education. Ordu Üniversitesi Hemşirelik Çalışmaları Dergisi 2(1):70-77

14. Bouvy JC, De Bruin ML, Koopmanschap MA (2015) Epidemiology of adverse drug reactions in Europe: a review of recent observational studies. Drug Saf 38(5):437-453

15. Castro-Pastrana LI, Carleton BC (2011) Improving pediatric drug safety: need for more efficient clinical translation of pharmacovigilance knowledge. J Popul Ther Clin Pharmacol 18(1)

16. Khan LM, Al-Harthi SE, Saadah OI (2013) Adverse drug reactions in hospitalized pediatric patients of Saudi Arabian University Hospital and impact of pharmacovigilance in reporting ADR. Saudi Pharm J 21(3):261266

17. Aagaard L, Hansen EH (2010) Adverse drug reactions reported for systemic antibacterials in Danish children over a decade. Br J Clin Pharmacol 70(5): 765

18. Impicciatore $P$, Choonara I, Clarkson A, Provasi D, Pandolfini C, Bonati M (2001) Incidence of adverse drug reactions in paediatric in/out-patients: a systematic review and meta-analysis of prospective studies. $\mathrm{Br} J$ Clin Pharmacol 52(1):77-83

19. Smyth RMD, Gargon E, Kirkham J et al (2012) Adverse drug reactions in children - a systematic review. PLoS One 7(3):e24061

20. Li H, Guo X-J, Ye XF et al (2014) Adverse drug reactions of spontaneous reports in shanghai pediatric population. PLoS One 9(2):e89829

21. Carnovale C, Brusadelli T, Zuccotti G et al (2014) The importance of monitoring adverse drug reactions in pediatric patients: the results of a national surveillance program in Italy. Expert Opin Drug Saf 13(sup1):1-8

22. Gallagher RM, Bird K, Mason J et al (2011) Adverse drug reactions causing admission to a paediatric hospital: a pilot study. J Clin Pharm Ther 36(2): 194-199

23. Gallagher RM, Mason JR, Bird KA et al (2012) Adverse drug reactions causing admission to a paediatric hospital. PLoS One 7(12):e50127

24. Gholami K, Babaie F, Shalviri G, Javadi MR, Faghihi T (2015) Pediatric hospital admission due to adverse drug reactions: Report from a tertiary center. J Res Pharm Pract 4(4):212

25. Kurian J, Mathew J, Sowjanya K et al (2016) Adverse drug reactions in hospitalized pediatric patients: a prospective observational study. Indian J Pediatr 83(5):414-419

26. Sindhu AR, Sebastian M, Panicker PR et al (2019) A study on adverse drug reactions in hospitalized pediatric patients in a Tertiary Care Hospital. J Appl Pharm Sci 9(09):072-076

27. Vázquez-Alvarez AO, Brennan-Bourdon LM, Rincón-Sánchez AR, Islas-Carbajal MC, Huerta-Olvera SG (2017) Improved drug safety through intensive pharmacovigilance in hospitalized pediatric patients. BMC Pharmacol Toxicol 18(1):79

28. Rivas AB, Arruza L, Pacheco E, Portoles A, Diz J, Vargas E (2016) Adverse drug reactions in neonates: a prospective study. Arch Dis Child 101(4):371376

29. Dash M, Jena M, Mishra S, Panda M, Patro N (2015) Monitoring of Adverse Drug Reactions in Pediatric Department of a Tertiary Care Teaching Hospital: A Hospital Based Observational Study. Int J Pharm 4(4):69-76
30. Rdl S, Díaz-Agudelo D, Burgos-Flórez FJ, Vaca C, Serrano-Meriño DV (2016) Adverse drug reactions in hospitalized Colombian children. Colombia Médica 47(3):142-147

31. Nobili A, Licata G, Salerno F et al (2011) Polypharmacy, length of hospital stay, and in-hospital mortality among elderly patients in internal medicine wards. The REPOSI study. Eur J Clin Pharmacol 67(5):507-519

32. Soldin OP, Chung SH, Mattison DR (2011) Sex differences in drug disposition. Biomed Res Int 2011

33. Walter SR, Day RO, Gallego B, Westbrook JI (2017) The impact of serious adverse drug reactions: a population-based study of a decade of hospital admissions in New South Wales, Australia. Br J Clin Pharmacol 83(2):416-426

34. Fasipe OJ, Akhideno PE, Owhin OS (2019) The observed effect of adverse drug reactions on the length of hospital stay among medical inpatients in a Nigerian University Teaching Hospital. Toxicol Res Appl 3:2397847319850451

35. Vlahovic-Palcevski V, Morovic M, Palcevski G (2000) Antibiotic utilization at the university hospital after introducing an antibiotic policy. Eur J Clin Pharmacol 56(1):97-101

36. Carrasco-Garrido P, de Andrés LA, Barrera VH, de Miguel GÁ, Jiménez-García $R$ (2010) Trends of adverse drug reactions related-hospitalizations in Spain (2001-2006). BMC Health Serv Res 10(1):287

37. Trifirò G, Calogero G, Ippolito FM et al (2005) Adverse drug events in emergency department population: a prospective Italian study. Pharmacoepidemiol Drug Saf 14(5):333-340

38. McAuley L, Tugwell P, Moher D (2000) Does the inclusion of grey literature influence estimates of intervention effectiveness reported in meta-analyses? Lancet. 356(9237):1228-1231

\section{Publisher's Note}

Springer Nature remains neutral with regard to jurisdictional claims in published maps and institutional affiliations.

\section{Submit your manuscript to a SpringerOpen ${ }^{\circ}$ journal and benefit from:}

- Convenient online submission

- Rigorous peer review

- Open access: articles freely available online

- High visibility within the field

- Retaining the copyright to your article

Submit your next manuscript at $>$ springeropen.com 